\title{
Liberal Foundations of Democratic Authority ${ }^{1}$
}

Andrew Lister

Queen's University

\author{
Representation, Vol. 46, No.1, 2010, pp.19-34
}

Final Version available online: http://www.tandfonline.com/toc/rrep20/46/1

\section{Introduction}

If all we cared about was procedural equality, we could make our political decisions by flipping coins. If all we cared about was the quality of the decisions made, we could let experts make our political decisions. Is democracy then a compromise between equality and accuracy? David Estlund argues not. Our commitment to democracy can be derived, he claims, from a familiar liberal principle of legitimacy. The exercise of political power is only justifiable if it is justifiable to everyone concerned, where "justifiable to" means, roughly, acceptable without the need for religious or philosophical conversion, so long as one espouses one of the set of points of view deemed reasonable or otherwise qualified. Any claims to authority must pass this qualified unanimity test. Even though some people do know more than others about politics and policy, the average person is not unreasonable to doubt this superior knowledge, or to doubt that experts are of good will, or at least to suspect that expertise is correlated with counteracting biases, given that the acquisition of expertise is not a random process. Democracy thus emerges as the epistemically best decision-procedure that is not reasonably rejectable. Other procedures might generate better outcomes, but the extra authority involved in these non-democratic procedures does not pass the qualified acceptability test. Epistemic proceduralism is not a middle way between equality and accuracy because, as Ben Saunders explains in his essay, it ascribes no independent role to procedural fairness (Saunders 2010). It is concerned solely with the epistemic merits of decision-procedures, subject to the requirement that these merits be sufficiently evident to satisfy the liberal demand for acceptability to all qualified points of view. Surprisingly, then, 
the case for democracy rests on the liberal demand that legitimate relationships of authority be invulnerable to qualified objections (along with the claim that the epistemic benefits of undemocratic procedures are subject to such objections). ${ }^{2}$

The purpose of this paper is to explore a problem that arises from the fact that the qualified acceptability requirement applies to itself. Self-application implies that all doctrines identified as reasonable or qualified must recognize each other and only each other as qualified, a condition Estlund refers to as "insularity" (55). The broader the range of views identified as qualified, however, the less likely all such doctrines are to recognize each other as qualified. Conversely, the narrower the range of views identified as qualified, the less likely qualified points of view are to recognize only each other as qualified. Whatever the range of qualified views, barely qualified views at either end of the spectrum must have an implausible asymmetry in the range of views they recognize as qualified. Moreover, the standard of qualification is not the only element of the principle of public justification that needs to be specified. Because the principle of public justifiability is an idealized unanimity requirement, it needs a default that obtains in the absence of unanimity (on the part of qualified points of view). Yet there is likely to be reasonable disagreement about what the appropriate default is. A philosophical account of legitimate authority will have to be insular both with respect to the standard of qualification and the choice of a default, raising doubts about whether insularity is attainable.

Lack of insularity would not be a problem if the principle of public justifiability did not apply to itself. Are there principled grounds for denying self-application, or would any such move merely be "dogmatic," as Estlund says (57)? One possibility would be to argue that only reasons for the exercise of political power need be acceptable to all qualified points of view, and 
that as a limit on the permissible grounds for state action, the qualified acceptability requirement need not itself be acceptable to all qualified points of view. A second possibility is to adopt a convergence rather than a consensus interpretation of public justifiability, so that no particular reason justifying a particular policy need be acceptable to all qualified points of view, so long as the policy itself is. A third possibility is to water down the standard of qualified acceptability, so that only the basic, motivating grounds for the exercise of political power need be acceptable to all qualified points of view, not all of the assessments of fact and judgments about weighting of values that figure in the full justification of a particular law or policy. This third approach is the most plausible, but it is ruled out by Estlund's insistence that all doctrines involved in the justification of the exercise of political power be publicly justifiable. Epistemic proceduralism is for the same reason vulnerable to a version of the asymmetry objection to political conceptions of justice. If reasonable disagreement blocks state action based on contested conceptions of the good, why do not the reasonable objections of libertarians block redistributive economic policies? The liberal principle that Estlund uses to justify democracy would seem to limit rather severely the scope of legitimate collective authority. Estlund may have justified democratic government, but the strict liberal demand for legitimacy seems to block the possibility of a democratic society.

\section{Self-Application, Insularity, and the Distinctness of Political Liberalism}

One of the objections frequently made against the liberal demand for public justifiability is that the principle is self-defeating, since it enjoins avoidance of controversy and is itself controversial. Not everyone believes that political legitimacy depends on "higher-order impartial- 
ity," Thomas Nagel recognizes, "and if we forcibly impose political institutions because they do not meet it (and block the impositions of institutions that do not) why are we not being just as partial to our own values as someone who imposes a state religion?" (Nagel 1987: 222) Disagreement-avoiding principles are contingently self-defeating, Joseph Raz argues, if they are "absolute" (giving lexical priority to disagreement-avoidance) and "comprehensive" (applying to all disagreements). Any such principle will be controversial, and hence cannot be relied upon in political decision-making (Raz 1998: 30). One can reformulate the principle so that it does not apply to itself, e.g. 'political decisions must rely on no controversial principles other than the principle of public justification'. Like Raz, however, Estlund is sceptical that there is any independent reason for formulating the principle in this way. Accordingly, he defines the scope of the demand for public justification very broadly. No doctrine is admissible at any stage of political justification unless it is acceptable to qualified points of view (53), and the term "doctrine" captures all kinds of reasons that one might invoke. "I use the term 'doctrine' "to cover a wide variety: factual statements, principles, practical proposals, moral judgments, and so forth. Thus an acceptability requirement is itself a doctrine" (44). ${ }^{3}$

One variable missing from the preceding analysis is the necessary idealization of the parties and points of view whose acceptance is deemed necessary by the principle of public justification. If legitimate authority depended on there being a justification everyone in fact accepted, the objections of the crazy and the vicious would defeat plainly sound and widely-accepted principles (4). The idea of public justifiability is supposed to be a moral constraint on the exercise of political power, yet there would be nothing moral in providing a veto over exit from the state of nature to the largest, most sadistic brute. The morally salient fact that is supposed to be 
relevant to the exercise of political power is the expected persistence of disagreement that is in some sense reasonable. We are supposed to recognize that deliberation between people fully able and willing to reason together honestly about what is true and good will not converge, for some range of religious, philosophical, and ethical questions, at least not quickly enough so that all of the reasonable citizens of a democratic society could share the same general doctrine. Estlund abstracts away from the question of exactly what reasonableness consists in by speaking of "qualified" points of view. The principle of public justification is thus a "qualified acceptability requirement," in his terminology, or a 'QAR' for short (45). The fact that a particular QAR is controversial in a particular society does not make it self-defeating, because only qualified points of view need accept the QAR.

Raz is aware of the fact that a reasonableness condition would allow escape from self-defeat, but thinks such a condition involves a form of unequal treatment.
A prima facie objection to restricting the required consent in that way is that every person counts. The life and well-being of those with unreasonable views are just as likely to be affected by the ac- tions of political authorities as the life and well-being of other people. Moreover, their life and well- being are of moral consequence. They cannot be ignored, and if the other people's agreement is required, so should theirs be. ( $\operatorname{Raz} 1998: 33)$

The life and well-being of the unreasonable are undeniably of moral consequence. The views of the unreasonable cannot be ignored by denying them the vote or the right to free speech. The question is only whether there is a morally objectionable form of unequal treatment in my deciding how to exercise my own democratic voice according to a QAR that considers only qualified objections. There is clearly a kind of differential consideration of opinions in the moral principle I am using to determine how I will vote, but whether this difference amounts to substantively unequal treatment is much less clear. On certain accounts, at least, the commitment to public reason is itself an interpretation of what equal respect requires (Larmore 1999). 
Despite its limited focus on qualified points of view, the QAR is not out of danger of selfdefeat, for it is not a matter of course that all qualified points of view will accept the QAR. Estlund labels the set of qualified points of view ' $C$ '. Suppose $C=$ the set of redheads. Many redheads would reject this specification of QAR; they would deny that acceptability to redheads is necessary for the legitimate exercise of political power (55). QAR REDHEADS $_{\text {would therefore not }}$ achieve "insularity," the situation in which each member of $\mathrm{C}$ recognizes the "rejection rights" of all and only members of C (55). ${ }^{4}$ Its lack of insularity would seem to imply that QAR REDHEADS is self-defeating, but Estlund prefers to call non-insular QARs "self-excluding" (54), meaning that a non-insular QAR excludes itself from political justification. ${ }^{5}$ Strictly speaking, a proposition is self-defeating only when its truth implies its falsity. The truth of a non-insular QAR does not imply its falsity, but rather its inadmissibility to political justification. Yet for a theory of democracy that rests on a QAR, self-exclusion (from political justification) is just as bad as selfdefeat.

Still, a particular QAR might be insular (hence not self-excluding in Estlund's terms or not self-defeating in Raz's terms) if we specify C more intelligently, not as the set of redheads, but (for example) as the set of reasonable citizens, à la Larmore or Rawls (willingness and ability to reason with others sincerely, recognition of the existence of burdens of judgment, etc.). The problem is that there is not only one insular version of C. It might be, for example, that all members of a particular religious sect recognize the rejection rights of all and only their co-religionists. Estlund concludes from this "impervious plurality of insular groups" that political liberals must assert the truth of their acceptability requirement, and the truth of a particular specification of the acceptability requirement, which identifies $\mathrm{C}$, the set of qualified points of view. 
Political liberalism cannot simply be reasonable, or acceptable to qualified points of view, because it needs to say who counts as qualified, and there are many possible standards of qualification that might be acceptable to all points of view identified as qualified (57). The QAR must therefore have both truth and qualified acceptability, while other doctrines need only qualified acceptability (Estlund 1998b: 266).

Estlund agrees with Raz that there can be no political justification without appeal to the truth at some point. Estlund says that his political liberalism is "substantive" rather than "wholly procedural" because it asserts the truth of its QAR, not just its qualified acceptability. Raz's claim that "there can be no justice without truth" is wrong in one respect, however. Political liberalism is fundamentally a theory of legitimacy, not justice. It must claim truth for its fundamental principle of legitimacy, but legitimate conceptions of justice need only be acceptable to qualified points of view, because of the truth about the priority of legitimacy over justice. A society well-ordered by justice as fairness (for example) might not be truly just, "but it may yet be just in the only sense of justice that can legitimately be brought to bear in the fixing of political obligations and state powers, that is, being well-ordered according to a conception of justice that is acceptable too all reasonable citizens" (63).

Having laid out Estlund's QAR, and partially defended it against the objection that it refutes or undermines itself, I want now to raise a potential problem that concerns the requirement of insularity. The general question is whether there is a defensible specification of $\mathrm{C}$ such that all members of C accept $\mathrm{QAR}_{\mathrm{C}}$. Estlund is aware that insularity may be hard to come by. "Doesn't it seem likely," he asks rhetorically,"...that there is qualified disagreement about who is qualified?" (60). He admits that if the criterion for qualification is too broad (i.e. if it is too lax, 
and accepts too many views as qualified), some qualified views will not accept the criterion (60). However, I think that this admission understates the severity of the problem, because narrowing the range of views included in $\mathrm{C}$ is not sufficient to ensure insularity.

Let us simplify by supposing that all doctrines can be arrayed in one dimension. $\mathrm{QAR}_{\mathrm{C}}$, a particular specification of QAR, picks out some range of doctrines $\mathrm{C}$ as qualified. But each of these doctrines $D_{i}$ has its own set of views $C_{i}$ that it thinks qualified. $C_{i}$ includes $D_{i}$, because if one believes a doctrine one necessarily thinks it reasonable. A natural question to ask is how the location of a particular doctrine such as $\mathrm{D}_{1}$ relates to the location of the doctrines it recognizes as qualified, the set $\mathrm{C}_{1}$. Assume first that there is a correlation between a view's location and the locations of the views it deems qualified. Suppose, for example, that each view $D_{i}$ is located at the center of its qualification set $\mathrm{C}_{\mathrm{i}}$, and that they each have the same range.

Figure 1: Qualification Sets: $C_{i}$ correlated with $D_{i}$

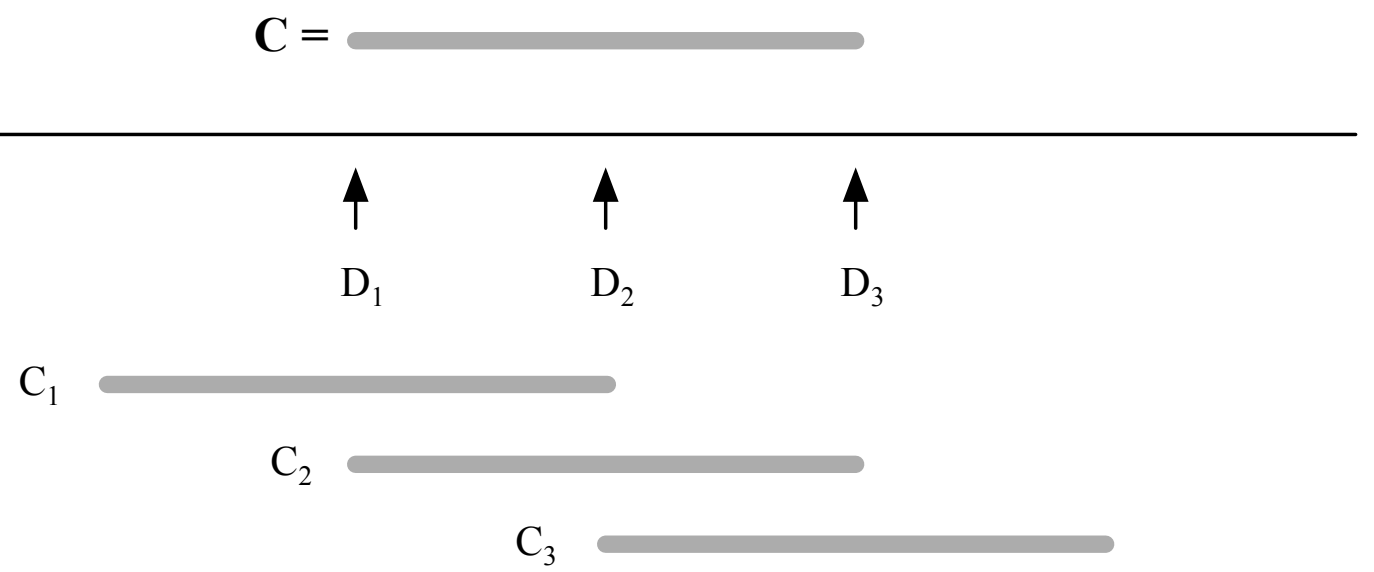

Figure 1 depicts a case in which $\mathrm{QAR}_{\mathrm{C}}$ is not insular, most obviously because $\mathrm{D}_{1}$ does not accept $\mathrm{D}_{3}$ as qualified and vice versa. The problem seems to be that $\mathrm{C}$ is too broad. To achieve insularity, we might narrow $\mathrm{C}$. 
Figure 2: Qualification Sets: $C_{i}$ correlated with $D_{i}$, Narrow $C$

$$
\mathrm{C}=
$$

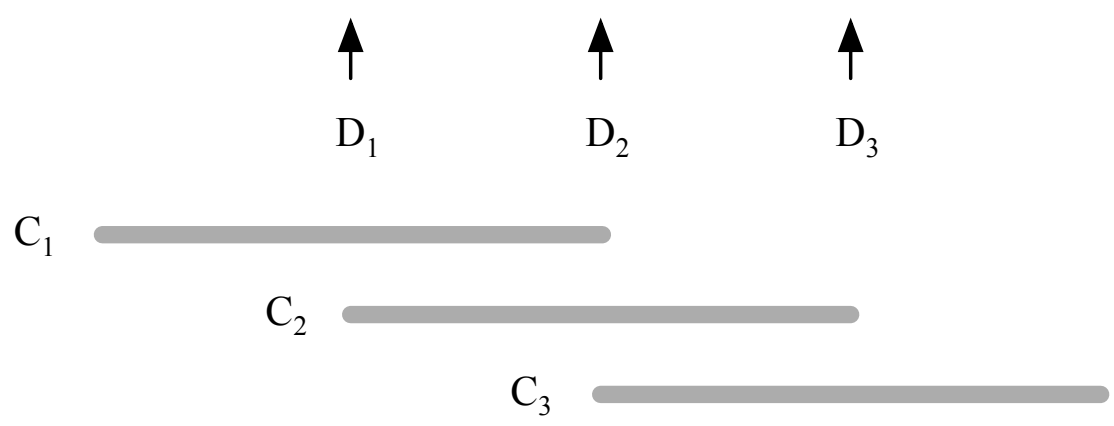

Now that we have excluded $\mathrm{D}_{3}$ from the set of qualified points of view, our two remaining qualified points of view $D_{1}$ and $D_{2}$ recognize each other as qualified. QAR ${ }_{C}$ is still not insular, however, because $D_{1}$ and $D_{2}$ each recognize as qualified views that the other does not (for $D_{2}$, views to the left of $\mathrm{D}_{1}$, and for $\mathrm{D}_{1}$, views to the right of $\mathrm{D}_{2}$ )

We get the same result if we keep our broader $\mathrm{C}$, while expanding the range of views each $\mathrm{D}$ recognizes as qualified, as in the case below:

Figure 3: Qualified Sets: $C_{i}$ correlated with $D_{i}$, Broad $C_{i}$

$$
\mathbf{C}=
$$
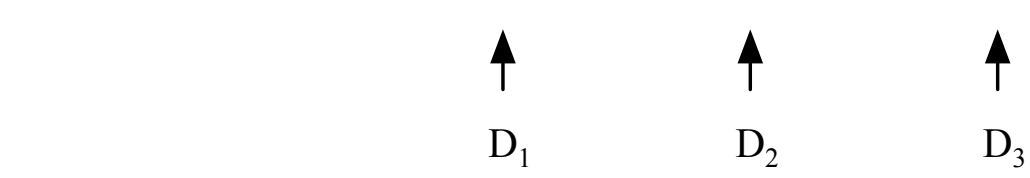

$\mathrm{C}_{1}$

$\mathrm{C}_{2}$

$\mathrm{C}_{3}$

Again, all of the views identified by $\mathrm{QAR}_{\mathrm{C}}$ as qualified recognize each other as qualified. How- 
ever, $\mathrm{QAR}_{\mathrm{C}}$ is still not insular, because it is not the case that the members of $\mathrm{C}$ recognize only the members of $\mathrm{C}$ as qualified. All members of $\mathrm{C}$ recognize that the exercise of political power must be acceptable to all members of $\mathrm{C}$, but some members of $\mathrm{C}$ think that the exercise of political power must also be acceptable to some views outside of $\mathrm{C}$.

In order to achieve insularity in this one-dimensional scenario, we have to suppose that the further a view is from the middle of our spectrum, the further it lies towards the edge of its qualification set, as in the case below.

Figure 4: Qualification Sets: $C_{i}$ uncorrelated with $D_{i}$

$$
\mathbf{C}=
$$

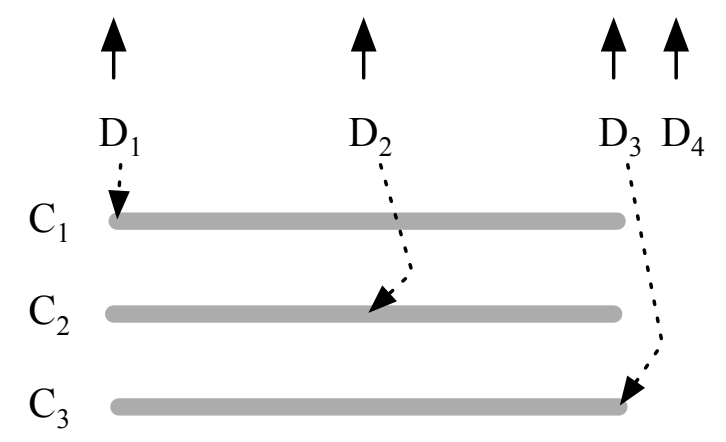

In this example, $\mathrm{QAR}_{\mathrm{C}}$ is insular, because there is no correlation between the location of a view $D_{i}$ and the location of its qualification set $C_{i}$ (and because the qualification sets all have the same range). These conditions seem quite demanding. The qualifications sets of the views at the outside edges of qualification display a puzzling discontinuity, and a strong asymmetry. How is it that a view such as $D_{3}$ cannot recognize a neighbouring view $D_{4}$ as reasonable, but can recognize a distant view $\mathrm{D}_{1}$ as reasonable? Those in the middle might recognize those on either extreme as reasonable, but those at either end have a hard time accepting the reasonableness of those on oth- 
er extreme. The broader the range of $\mathrm{C}$, the greater the asymmetry, for barely qualified $\mathrm{D}_{\mathrm{i}}$ at either end of the spectrum.

One possible response to this objection would be to claim that being qualified is not a matter of more or less, but rather a status that one either has, or not. ${ }^{6}$ Without a spectrum, the problem disappears. It is true that qualification need not be located on any ordinary left-right ideological spectrum, but most plausible criteria of qualification are going to be the kinds of traits that can be present to greater or lesser degrees, such that a question can arise about the threshold at which we will consider a doctrine to count as qualified. Perhaps disagreement is only possible about the lower end of the spectrum, but this is not obvious. For some traits plausibly associated with moral qualification it is plausible to think that there can be too much of a good thing, as well as too little. For example, reasonableness is often thought to involve a willingness to see things from other people's perspectives, to put oneself partially in their mindset as well as in their shoes. Yet it is possible to carry role-reversal arguments across disagreement too far. Someone who takes seriously how things look from the perspective of a lunatic or a moral monster is like Frost's liberal who can't take his own side in an argument (Nagel 1987: 215). So long as the traits upon which qualification depends vary continuously, and so long as doctrines differ in their assessments of these traits, the problem of non-insularity threatens.

Another possible response is to distinguish the rule that picks out members of $\mathrm{C}$ from the set of members picked out by applying that rule correctly. ${ }^{7}$ Perhaps insularity requires only that all members of $\mathrm{C}$ accept the rule identifying members of $\mathrm{C}$, not a list of the members $\mathrm{C}$ identified by name. Suppose, for example, that all redheads accepted the demand that relationships of legitimate authority be acceptable to redheads, but disagreed about whether Andrew is a redhead. 
Qualified points of view might disagree about exactly where to locate the boundaries between brown, red, and blond, but agree with the general rule that all and only redheads are qualified. Of course, we still need to know who is really a redhead, in order to know that they all accept this general rule for picking out members of C. Also, in practice we need to make determinations about who counts as reasonable or qualified; we need to say, for example, that doctrines committed to a fetal right to life based on belief in immediate ensoulment are unreasonable (see, for example, Williams 2000: 208). Perhaps the correlation between the color of one's hair and one's views about where to locate the boundaries between brown, red, and blond would be small, so that we would be very close to the situation depicted in Figure 4, but for more plausible criteria of qualification, this seems to be a demanding assumption. The basic question is whether there is a correlation between the extent of a doctrine's qualification (or the ease with which it passes the threshold of qualification), and its views about the proper boundaries (or threshold) of qualification. Insularity requires that there be no such correlation, as in the case of hair colour, where those with bright red hair are just as likely to have a high standard of redness as are those with only slightly red hair. It seems to me that this is a demanding assumption. Those who are only barely reasonable are likely to have different conceptions of reasonableness than those fully reasonable.

Yet Estlund has a simple, and seemingly unassailable response to all doubts about whether insularity is possible; acceptance of the true standard of qualification is itself a criterion of qualification. "The problem [of self-exclusion from political justification, i.e. what Raz was calling self-defeat] is avoided if we say that one feature that a person must have in order to count as qualified is to accept the acceptance criterion including its correct account of qualified people" 
(61). Estlund is aware that this response may seem question-begging. He points out, however, that we do accept that belief in certain propositions is a criterion of qualification. We hold people to be unreasonable if they do not accept that people are morally free and equal, or if they deny that reasonable people can disagree. Accepting the true account of qualification is just one more view people have to accept to count as qualified. Yet acceptance of the true standard of qualification cannot be so easily assimilated to other criteria of qualification that involve the acceptance of particular views.

Estlund insists that, if it is not to be dogmatic, the QAR must be acceptable to all qualified points of view as well as being true. This rejection of dogmatism assumes that truth and qualified acceptability are two distinct criteria. And so they are, in the case of views such as the claim that we are all morally free and equal. It is an open question whether all those who believe in universal freedom and equality also believe that political authority must be acceptable to all and only themselves, just as it was an open question whether all redheads accept $Q A R_{\text {REDHEADS. }}$ In contrast, it is true by definition that all those who accept the true standard of qualification accept that political authority should be acceptable to all those who accept the true standard of qualification. There are not two questions: who is qualified, and whether qualified people accept the standard of qualification. There is simply a stipulation that to be qualified everyone must accept the true standard of qualification, so that no matter what the true standard of qualification turns out to be, people so-qualified accept it. Making acceptance of the true standard of qualification a criteria of qualification effectively exempts this aspect of the QAR from self-application, and to this extent makes the QAR dogmatic. 


\section{Self-Application and the Default}

The standard of qualification is not the only respect in which QAR needs to be specified, and which could be the subject of reasonable disagreement. The QAR is a unanimity requirement, and as such, it ordinarily requires a default. With a balance-of-reasons or majority standard, it does not matter which of options A or B we label the action, and which we label inaction. Even if we incorrectly label A the action and B the option of doing nothing, we should still choose B if the balance of reasons tilts in its favour. With a unanimity requirement, however, we need to get these labels right. If neither A nor B achieves unanimous approval (among qualified points of view), we need to choose the option that amounts to not exercising political power; we need to know which of $\mathrm{A}$ and $\mathrm{B}$ is the option that involves doing nothing and exercising no power.

It is possible to demand (qualified) unanimity but to reject any choice of a default, if we acknowledge some higher standard of choice than legitimacy. This seems to be the position Thomas Nagel adopts. "Given the actual range of values, interests and motives in society, and depending on one's standard of justification, there may not be a legitimate solution, and then one will have to choose between illegitimate government and no government" (Nagel 1987: 218). Nagel's statement that we will have to choose between illegitimate government and no government implies that there is a higher standard than legitimacy, a standard to which we may rightly appeal in making the choice of an illegitimate but nonetheless in some sense justified government. In contrast, Estlund is I think committed to the view that legitimacy comes first, and that in the absence of adequate public justification (i.e. when QAR is not satisfied), we may not exer- 
cise political power. ${ }^{8}$

Estlund explicitly discusses a weak form of default: the tie-breaker. If there are no reasons for and against the exercise of political power, or if there are equally balanced reasons, not exercising power (non-authority) wins.

Consider the idea that the "default" condition is the absence of authority... The idea that non-authority is the "default" might... mean that there is no authority unless some positive moral case can be made for it. Absent moral considerations in either direction, a person is free from authority. non-authority requires no reason, on this view, and is the default in precisely that sense... So understood, I accept the idea that non-authority is the default. As I have argued, the qualified acceptibility requirement burdens authority (and legitimate power) with the need for justification in terms acceptable to all qualified points of view. Absent such justification, the default condition is the absence of the authority or legitimate power in question (120-1)

The justification of this default might be that there is always something morally bad about coercive political authority, so that the exercise of such authority requires a positive balance of reasons, ties defaulting to non-authority. Yet implicit in Estlund's qualified acceptibility requirement is a stronger default. Even if there is a positive balance of reasons (truly, or in my view), the exercise of political power is illegitimate unless acceptable to all qualified points of view. The QAR thus imposes the requirement that the balance of reasons be so strongly in favour of the exercise of political power that one would be unreasonable (or otherwise unqualified) to think the balance negative. Not only is inaction or non-authority the default in cases of ties, it is the default for cases in which the balance of qualified reasons is positive but not conclusively so. Another way of arriving at this demand for conclusive justification is to ask whether views about where the balance of QAR-satisfying reasons lies must themselves pass QAR. Since such views count as "doctrines," under Estlund's expansive account of the term, it seems that they must. Thus for the exercise of political power to be legitimate, all qualified views must accept that the balance of public reasons is positive. ${ }^{9}$

There will often be room for reasonable disagreement about which option should count as 
the default. ${ }^{10}$ We are agreed, of course, that the default is "no legitimate authority," but which of options A and B constitute no (or less?) legitimate authority? It may seem that the answer is obvious, because there is no ambiguity about what a state of nature is. If option $\mathrm{A}$ is that no one has the right to make and enforce any authoritative rules, then so long as option B involves the enforcement of some authoritative rule, A is the default. As soon as we have a state doing something, however, the addition of an extra law does not necessarily mean that the state is exercising power more. For example, if the state has a law against assault in public, adding a law against domestic assault makes it more active in one respect - beating one's spouse is no longer legally permissible - but less active in another respect - coming to the defense of beaten spouse no longer counts as an assault on the batterer, but the prevention of a crime.

A related problem concerns the level at which we apply the demand for idealized unanimity. Do we apply the QAR globally, to one choice between a series of sets of laws and policies ('zoomed-out', as it were), or do we apply it locally, to many discrete choices between disaggregated laws and policies ('zoomed-in')? At the global level, we might face a choice between a perfectionist state, a non-perfectionist state, and no state. Unless one has a very rosy view of the state of nature, many specifications of a perfectionist state would be unanimously reasonably preferred to no state at all, and so legitimate if chosen democratically. Applied at a more local level, the QAR will rule out a lot more state action. It is unreasonable to reject police protection of property, but reasonable to reject taxation of redistribution, one might argue; it is unreasonable to reject having laws against murder, but reasonable to reject laws against abortion. What results the QAR generates in these cases depends crucially on whether it is applied to the two choices separately or to one aggregated choice (protection of property and redistribution sep- 
arately, or choice of a system of property rights; murder and abortion separately, or choice of the scope of "murder"). Perhaps the correct approach is to insist on application at the level of maximum logically feasible disaggregation, i.e. zoom-in to the most fine-grained level of description of policy choices such that the different choices are still logically independent. There is likely to be room for reasonable disagreement, however, about which choices can be evaluated independently of others.

Suppose now that we have decided to apply the QAR at the level of whole systems of property rights, which we take to include so-called "redistribution". We agree that both an egalitarian and a libertarian system of property rights are preferable to none at all. It seems then that we are permitted to choose between the two democratically, consistent with the QAR. However, if the exercise of political power must meet the QAR (or else we default to no such exercise), it stands to reason that the exercise of more political power must meet the QAR, or else we default to less. "Some" vs. "none" is just a special case of "more" vs. "less". It seems reasonable, therefore, to adopt an incremental version of the QAR for three-option cases in which the options can be ranked as to the degree of coercive political authority they involve. Now, I am sympathetic to the view that "redistribution" is no more coercive than enforcement of property rights; either the state is forcibly taking away some of my wealth and giving it to others, or it is forcibly protecting that wealth from others. Yet these questions are likely to be subject to reasonable disagreement. If all doctrines involved in the justification of the exercise of political power must pass the QAR, and if doctrines specifying the QAR count as such doctrines, then both the set of points of view deemed qualified and the identification of the default that will obtain when the QAR is not met must pass QAR. The QAR must now be insular in two dimensions, compounding the difficulties 
with insularity canvassed in the previous section.

\section{Ways to Avoid Self-Application}

Given the difficulties self-application creates, it might be useful to look for ways of justifying what Estlund calls dogmatic political liberalism: political liberalism based on a QAR that need not itself be acceptable to all qualified points of view. I want to present three ways to exempt the QAR from the demand from qualified acceptability, and consider their costs.

The first questions the claim that there would something wrong in letting the QAR have authority over those who conscientiously (and reasonably, or qualifiedly) reject it. In what sense does the QAR have authority over anyone? The QAR is a constraint on the exercise of political power. There is therefore an important difference, one might argue, between exercising political power in a way that can only be justified by appeal to the QAR (assumed to be rejectable, now, by qualified points of view), and exercising political power for the sake of some particular, reasonably rejectable goal or value. The QAR does not say what we are to exercise political power for; it merely limits the range of purposes for which we can exercise political power. Therefore the authority it has over those who conscientiously reject it is qualitatively different than the authority an ordinary value or principle used to justify the exercise of political power would have over those who conscientiously reject it. Laws justifiable only by ordinary reasonably-rejectable values or principles force people to serve goals that they conscientiously reject; the QAR simply limits people's ability to use political power to make others serve goals they conscientiously reject. Therefore the QAR need not itself satisfy QAR.

Is this argument persuasive? Not as it stands, but it does suggest a way of reformulating 
QAR so as to avoid self-application. When is it necessary to invoke the QAR in political justification? Let us divide reasons into the twin categories of public and non-public, and for and against some law or other state action. The balance of public reasons for and against I will call the public case, and the balance of non-public reasons for and against the non-public case. ${ }^{11}$ In which circumstances will these citizens' accepting the QAR make a difference to what policy they support? Accepting the QAR makes no difference when the public and non-public cases are both positive or both negative, or when the public case in one direction outweighs the non-public case in the other. Accepting QAR can make a difference only if without it the public case would be outweighed by the non-public case. There are two possibilities:

1. Standard Situation: Non-public case supports action more than public case opposes. Without QAR, the agent supports action; accepting QAR would switch the agent's decision from act to not-act. An example might be opposition to abortion laws on the part of someone who thinks abortion wrong, but who also accepts QAR, and recognizes that the reasons for thinking abortion wrong do not satisfy QAR.

2. Alternate Situation: Non-public case opposes action more than public case supports. Without QAR, the agent opposes action; accepting QAR would switch the agent's decision from not-act to act. An example might be support for hate speech laws on the part of a comprehensive Millian liberal, who thinks that very broad free speech rights are essential to the realization of autonomy, but who recognizes that this conception of autonomy does not pass the QAR, and so supports hate speech laws on the public ground that such laws reduce the probability of harm to members of minority groups.

The alternate situation shows what is wrong with the idea that the QAR does not impose on any- 
one beyond the duty not to impose on others. In the alternate situation, citizens would prefer to do nothing, but, accepting the QAR, find themselves required to criminalize particular forms of speech. The QAR requires them, in this instance, to do something they conscientiously object to. Although it is true that the QAR merely removes potential reasons for state action, rather that offering a new reason of its own, it also removes potential reasons against state action, and therefore may in some cases tip the scales in favour of action.

Nonetheless, it is possible to reformulate the QAR so as to avoid applying to the alternate case. As currently formulated, the QAR applies to any reason invoked to justify acting or not acting, politically. We might reformulate the QAR as a restriction on reasons for state action, not against:

QAR*: All doctrines supporting the exercise of political power must be acceptable to all qualified points of view; doctrines opposed to the exercise of political power need not be. QAR avoids self-application, and so need not be insular. Only doctrines necessary to justify the exercise of political need pass $\mathrm{QAR}^{*}$, and in the standard case, QAR ${ }^{*}$ is not necessary to justify exercising power. When the non-public case supports action more than the public case opposes, one must deny QAR* to justify state action. Since in this case QAR* is not necessary to justify the exercise of political power, it does not apply to itself, and so need not be acceptable to all qualified points of view.

The fact that $\mathrm{QAR}^{*}$ registers no objection in the alternate situation is what it allows it to avoid self-application. This same fact is also what makes QAR* objectionable. Intuitively, there is something wrong with allowing a negative non-public case to trump a positive public case. When Socrates suggests not enforcing contracts in order to make people less materialistic (Re- 
public, 556b), we want to say that discouraging materialism, even by inaction, is not the state's business.

There is another way to avoid self-application, however, which is to distinguish between the exercise of political power and the reasons that support it, and to insist that only the exercise and not the underlying reasons need be acceptable to all qualified points of view. Estlund's version of the QAR is what Fred D'Agostino calls a "consensus" rather than a "convergence" account of public justification (D'Agostino 1996: 30). Estlund's QAR demands that all of the doctrines invoked at any stage of political justification be acceptable to all qualified points of view. However, if fundamentally what we want is for the exercise itself to be reasonably acceptable, why do we need to demand that it be acceptable for the same reasons? What would be wrong with a law or policy that was acceptable to all qualified points of view, based on each view's comprehensive set of reasons, even though a decision based only on shared reasons would go against the law in question? Why should we not pass the law in question, if no one reasonably objects, even though the reasons that pass QAR do not justify acting? We can formulate the following two versions of QAR, making explicit where they differ:

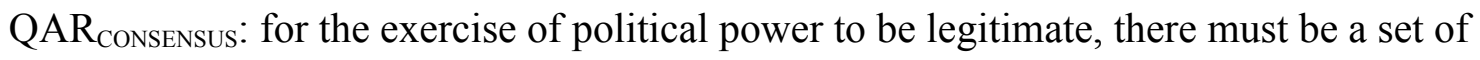
reasons acceptable to all qualified points of view that is sufficient to justify the exercise in question, but it need not be the case that each qualified point of view would accept this exercise of political power based on its comprehensive balance of reasons.

QAR $_{\text {CONVERGENCE: }}$ for the exercise of political power to be legitimate, it must be acceptable to all qualified points of view, but not necessarily for the same reasons.

On the convergence interpretation of public justification there is no constraint on the reasons that 
can justify the exercise of political power. The QAR can simply be true, and its truth does not imply that it needs to be acceptable to all qualified points of view. No doctrine need be acceptable to all qualified points of view, but only the law, policy or exercise of power in question. Convergence interpretations of the demand for public justifiability thus escape the demand for self-application, and the problems it creates.

Could Estlund avail himself of convergence justification, in his argument for democracy? Gerald Gaus and Kevin Vallier make the case for convergence justification in a recent article (Gaus and Vallier 2009). One advantage of their approach, in democratic terms, is that no one's reasons get ruled out. Even religious reasons are admissible to political justification, since all reasons are admissible. However, this admissibility is misleading. Although I may appeal to my full set of reasons to determine what law or policy I would prefer, the law or policy will not be legitimate unless it is acceptable to all qualified points of view. If citizens were to apply this criterion themselves, in political debate and decision-making, they would not invoke any of their own reasons to justify a particular law, but simply make arguments about what laws all qualified points of view accept. It is of course difficult to know what forms of the exercise of political power all qualified points of view would accept based on their comprehensive set of reasons. Gaus and Vallier do not expect citizens to figure this out, however. Laws are legitimate only if acceptable to all qualified points of view, but citizens are not meant to follow this standard in deciding what to say and do. It is rather the designers of institutions who must have the principle of legitimacy in mind, as they craft democratic institutions to maximize the making of legitimate laws by citizens and law-makers aiming at various personal and comprehensive objectives. This indirect form of justificatory liberalism is ingenious, but rather far from the traditional idea of 
public justification, and I presume Estlund would not be inclined to move in this direction.

If our QAR must apply to itself, but self-application will lead the QAR to exclude itself from political justification, a third solution would be to water down the standard of qualified acceptability, so that it is easier to meet. Nagel's response to the self-application problem takes this form. "It would be an impossibly restrictive condition on political power to say that its exercise may be justified only by appeal to premises that others could not reasonably reject." The impossibility of reasonable rejection "must come in at a higher level," Nagel claimed. For a particular exercise of political power to be legitimate, it must be "open ended in the possibility of its investigation and pursuit and not come down finally to a bare confrontation between irreconcilable points of view." The parties to the former kind of disagreement "can think of themselves as appealing to a common, objective method of reasoning which each of them interprets and applies differently" (Nagel 1987: 231-35). Such disputes involve differences in judgment about the appropriate weighting and application of common values or principles. The liberal standard of impartiality does meet its own criterion of impartiality, therefore, "because it is defendable, and attackable, by arguments of the right type," (Nagel 1987: 238) which is to say on grounds on the interpretation of impartiality itself (Nagel 1987: 223). To count as public, reasons need not be invulnerable to reasonable rejection, they need only be plausibly defendable based on some deeper, motivating values or principles that are not-reasonably rejectable. If I understand him correctly, Estlund does not take this approach to overcoming the self-application problems because he insists that all reasons involved in public justification must pass the QAR. The point of saying that a wide variety of things count as "doctrines," and that all doctrines must satisfy the QAR, is to say that each and every consideration necessary to justify decisions about the exercise 
of political power must be acceptable to all qualified points of view. If the QAR simply demanded plausible justifiability on the basis of some underlying grounds that are not reasonably rejectable, Estlund would not state the scope of the QAR in such uncompromising terms.

Consider Estlund's treatment of Mill's proposal to give the educated more votes. Ordinarily, one might object that this proposal involves procedural unfairness, an unequal distribution of political authority. But Estlund does not want to appeal to equal treatment in the decision procedure. Instead, he appeals to the claim that the extra authority the educated would have over the uneducated is reasonably rejectable. Estlund does not make things easy for himself, because he accepts that other things equal, education increases quality of rule (211). He argues, however, that it is reasonable to suspect that other things are not equal, because the processes that determine who gets educated are not random, and so may introduce counteracting biases; this the "demographic" objection (215-19). I have no quarrel with this argument, but merely want to underline how demanding Estlund's standard is. Mill's plural voting scheme would introduce "an element of rule of some by others" and so it must pass the qualified acceptability requirement (219). This requirement is not the Rawlsian / Nagelian requirement that plural voting be plausibly justifiable in terms of underlying values or principles that are not reasonably rejectable, but that it be conclusively justified, i.e. that the voting scheme itself not reasonably or 'qualifiedly' rejectable. Estlund therefore cannot accept Nagel's solution to the problem of self-application. Rejecting Nagel's solution to the self-application problem has costs, however. The weaker, Nagelian version of the public justifiability standard is essential to overcoming the objection that liberal legitimacy forces us to accept a minimal, nightwatchman state. Jonathan Quong calls this the asymmetry objection to political liberalism. "If reasonable people disagree just as much 
about justice as they do about the good life, then why are perfectionist reasons, but not reasons of justice, deemed illegitimate grounds for state action?" At first blush, the commitment to public justifiability would seem to lead to "a fairly libertarian view of legitimate state action" (Quong 2005: 302-03). This impression is misleading, Quong claims, for the liberal standard of legitimacy only demands plausible justification in terms (reasonably) shared premises, not unanimity (of the reasonable) as to substantive conclusions. If reasonable disagreements about the good life tend to be "foundational," while disagreements about justice tend to be "justificatory," and if liberal legitimacy only demands neutrality with respect to foundational disagreements, reasonably contestable justice-based policies may be legitimate while perfectionist policies will generally not be (Quong 2005: 303, 311). Quong's argument allows political liberals to be egalitarians too. Estlund's insistence that all doctrines involved at any stage of the justification of the exercise of political power pass QAR, and his broad definition of what counts as a 'doctrine', rule out Quong's response.

There is another way we can try to avoid Quong's asymmetry objection, and it is suggested by Nagel's response to the cases of nuclear weapons and the death penalty. We don't think that reasonable disagreement blocks state action in these cases, even though the disagreements over these issues seem just as foundational as does the disagreement over abortion. The difference, Nagel claimed, is that decisions about military and criminal policy are essential functions of the state. Who's to say what's an essential function of the state? Nagel's implicit criterion is made explicit in Jerry Gaus's argument from higher order unanimity, which I have already invoked (Gaus 2003: 159-60). Every reasonable person agrees that it is better to have some common policy about military and criminal matters, rather than having private militias (some armed 
with nuclear weapons) and Lockean vigilanteeism (minus the agreement as to the law of nature). In each case, two options A and B are reasonably rejectable against the other, but unanimously reasonably preferred to collective inaction. It is therefore legitimate to choose from the set of acceptable options democratically. This democratic escape clause works fine, but depends heavily on the level at which it is applied, and how the coerciveness of different policies is measured (if we adopt an incremental version of the public justifiability principle). This is the problem of the default, which is fatal if we demand insularity.

It seems, therefore, that Estlund's liberal defense of democracy narrowly circumscribes the domain of legitimate collective authority. His argument justifies democratic government, but may preclude the possibility of a genuinely democratic society, as egalitarians and democrats have traditionally conceived of it. Considered by itself, the ideal of democracy might require such a society, but liberal legitimacy does not permit the full realization of democracy, any more than it permits the full realization of justice. ${ }^{12}$ Liberal legitimacy justifies democratic decisionprocedures, but only within the limited sphere in which this rather libertarian liberalism permits collective decision-making.

1. This paper grew out of discussion on the Public Reason blog, and has benefited greatly from the comments I received from Jonathan Quong and Ben Saunders, as well as from my being able to read earlier drafts of their papers.

2. This paragraph is meant to summarize the main argument of Estlund's Democratic Authority (Estlund 2008). Henceforward all references to Democratic Authority will be made parenthetically in the text. 
3. "The acceptability requirement has a logically interesting feature. It says that political justification cannot appeal to doctrines that are not acceptable to all qualified points of view, and it is itself a doctrine appealed to in political justification. It says, then, that even it cannot be used unless it is acceptable in that way" (53).

4. "Each member of C... must think that acceptance by all and only the members of $\mathrm{C}$ is necessary for a doctrine's admissibility... This amounts to a requirement that $\mathrm{C}$ be an insular group in the following sense. Insularity requirement: Each member of C must recognize the rejection rights of all and only the members of $C^{\prime \prime}(55)$.

5. Raz uses the term "self-excluding" to refer to an acceptability requirement framed so as not to apply to itself, which Estlund calls "dogmatic" (57). Estlund reserves the term "self-excluding" for a QAR that does apply to itself, but which fails to meet its own standard, and therefore excludes itself from inclusion in political justification.

6. Thanks to Jonathan Quong for this objection.

7. This objection is also due to Jonathan Quong.

8. $\quad$ I accept the idea that non-authority is the default. As I have argued, the qualified acceptability requirement burdens authority (and legitimate power) with the need for justification in terms acceptable to all qualified points of view. Absent such justification, the default condition is the absence of the authority or the legitimate power in question" (120).

9. There is an ambiguity about what exactly has to pass the QAR: authority, the right to make rules imposing obligations on others, or legitimacy, the right to use force to ensure that others comply with the rules. The p.120 quote from Chapter 7 above suggests that 
the QAR applies to both. However, when Estlund distinguishes authority and legitimacy at the beginning of Chapter 3, he says that only a weaker form of the QAR applies to legitimacy. "I defend a certain sort of necessary condition on the legitimate exercise of political power: that it be justifiable in terms acceptable to all qualified points of view... Later, I will argue that the acceptability requirement applies only to legitimacy and not to authority, though there is a weaker counterpart there". In Chapter 7, Estlund states that "[a]uthority, by which I mean the moral power to require action - can, in principle, be established even without a generally acceptable justification if normative consent (the moral duty to consent to authority if offered the chance) is present." So the weaker standard that applies to authority rather than legitimacy is this: authority must be acceptable to all qualified points of view except in cases in which there is a moral duty to consent to authority. There can thus be a moral duty to consent to authority even where it is reasonable to reject this authority. Yet the central case meant to illustrate normative consent is that of a flight attendant who issues orders in an attempt to help the injured after a crash. Despicable Joe does not consent, but his non-consent to authority is null, Eslund argues, because he morally ought to consent (124). Is it not the case, however, that Joe is unreasonable not to consent? Isn't this the reason the flight attendant's instructions have authority over him despite his lack of consent? In contrast, wrongful refusal to consent to sexual relations is not generally null because such non-consent, even if wrong (in special circumstances) is not unreasonable. I will assume that legitimacy and authority stand and fall together, and that both must pass the QAR, but I'm not sure I've got Estlund's position quite right. 
10. In this and the following two paragraphs I draw upon my "Public Justification and the Limits of State Action" (Lister 2010).

11. It may seem misleading to speak of "the" non-public case, but let us suppose we are considering the situation from the perspective of a particular group of citizens, who share a particular comprehensive doctrine that supplies a set of non-public reasons.

12. "[T]he truth about justice, like the truth about salvation, may not be suitable for inclusion in a public conception of justice that seeks to justify the coercive exercise of collective political power" (Estlund 1998a: 108).

\section{References}

D'AGOSTINO, FRED. 1996. Free Public Reason : Making it Up as We Go. New York: Oxford University Press.

ESTLUND, DAVID M. 1998a. Liberalism, Equality, and Fraternity in Cohen's Critique of Rawls. The Journal of Political Philosophy 6: 99-112.

ESTLUND, DAVID M. 1998b. The Insularity of the Reasonable: Why Political Liberalism Must Admit the Truth. Ethics 108: 252-75.

ESTLUND, DAVID M. 2008. Democratic Authority: A Philosophical Framework. Princeton, NJ: Princeton University Press.

GAUS, GERALD F. 2003. Liberal Neutrality: A Compelling and Radical Principle. In Perfectionism and Neutrality: Essays in Liberal Theory, edited by Stephen Wall, and George Klosko. New York: Rowman \& Littlefield, Inc.: 137-65.

GAUS, GERALD F., AND KEVIN VALLIER. 2009. The Roles of Religious Conviction in a Publicly Justified Polity: The Implications of Convergence, Asymmetry and Political Institutions. Philosophy and Social Criticism 35 (1-2): 51-76.

LARMORE, CHARLES. 1999. The Moral Basis of Political Liberalism. The Journal of Philosophy 96 (12): 599-625.

LISTER, ANDREW. 2010. "Public Justification and the Limits of State Action." Politics, Philosophy, Economics 9 (3), forthcoming.

NAGEL, THOMAS. 1987. Moral Conflict and Political Legitimacy. Philosophy and Public Affairs 16: 215-40.

QUONG, JONATHAN. 2005. Disagreement, Asymmetry, and Liberal Legitimacy. Politics, Philosophy, Economics 4: 301-30. 
RAZ, JOSEPH. 1998. Disagreement in Politics. American Journal of Jurisprudence 43: 25-52. SAUNDERS, BEN. 2010. Estlund's Flight From Fairness. Representation.

WILLIAMS, ANDREW. 2000. The Alleged Incompleteness of Public Reason. Res Publica 6 (2): 199-211. 